\title{
Neurologists' understanding and management of conversion disorder
}

\author{
Richard A Kanaan, ${ }^{1}$ David Armstrong, ${ }^{2}$ Simon Charles Wessely ${ }^{1}$
}

\begin{abstract}
- An additional appendix 1 is published online only. To view this file please visit the journal online (http://jnnp.bmj.com).

'Department of Psychological Medicine, Institute of Psychiatry, King's College London, London, UK ${ }^{2}$ Department of General Practice, King's College London, London, UK
\end{abstract}

\section{Correspondence to}

Dr R Kanaan, Department of Psychological Medicine, P062. Weston Education Centre, Institute of Psychiatry, London SE5 9RJ, UK:

richard.kanaan@kcl.ac.uk

Received 25 October 2010 Revised 8 December 2010 Accepted 5 January 2011 Published Online First 16 February 2011

\begin{abstract}
Background Conversion disorder is largely managed by neurologists, for whom it presents great challenges to understanding and management. This study aimed to quantify these challenges, examining how neurologists understand conversion disorder, and what they tell their patients.
\end{abstract}

Methods A postal survey of all consultant neurologists in the UK registered with the Association of British Neurologists.

Results 349 of 591 practising consultant neurologists completed the survey. They saw conversion disorder commonly. While they endorsed psychological models for conversion, they diagnosed it according to features of the clinical presentation, most importantly inconsistency and abnormal illness behaviour. Most of the respondents saw feigning as entangled with conversion disorder, with a minority seeing one as a variant of the other. They were quite willing to discuss psychological factors as long as the patient was receptive but were generally unwilling to discuss feigning even though they saw it as their responsibility. Those who favoured models in terms of feigning were older, while younger, female neurologists preferred psychological models, believed conversion would one day be understood neurologically and found communicating with their conversion patients easier than it had been in the past.

Discussion Neurologists accept psychological models for conversion disorder but do not employ them in their diagnosis; they do not see conversion as clearly different from feigning. This may be changing as younger, female neurologists endorse psychological views more clearly and find it easier to discuss with their patients.

\section{INTRODUCTION}

Conversion disorder ('hysteria') has been described as a 'crisis' for neurologists today, a crisis in understanding and communicating. ${ }^{1}$ Neurologists in the 19th century faced a similar crisis as it became clear that conversion had no detectable neuropathology, and it became common to assimilate it with feigning. ${ }^{2}$ Freud transformed hysteria into a psychiatric disorder in the 20th century but as Freudian models decline and a neuropathology of conversion is still lacking, today's neurologists once again face a disorder without an accepted model. Will they have absorbed the teachings of psychoanalysis or will they react as many of their predecessors did, and dismiss conversion as feigning?

Stories abound of the dismissive attitude of neurologists towards conversion ${ }^{3}{ }^{4}$ but this has not been subjected to rigorous scrutiny. We aimed to address this through a mixed methods assessment of the attitudes of neurologists to the nature of conversion and its management. We previously examined the approach of 22 consultant neurologists, ${ }^{5} 6$ exploring their understanding and management of conversion disorder (CD) in depth. They told us, in brief, that they accepted psychological models for conversion but did not employ them in their clinical practice, instead distinguishing conversion from other unexplained conditions by its inconsistency and other patient characteristics. They were divided on the distinction from feigning, with many seeing conversion and 'malingering' as merging into one, and liked to see themselves as 'agnostic' about explanations that were not in terms of neuropathology. They were guided by the receptivity of their patients as to how psychological to make their eventual explanations but did not discuss their suspicions about feigning. They described their communications as much easier now than those they had seen in training. The improved communication came at a truth telling cost, however, since it sometimes resulted in a changed diagnosis. This study aimed to test, quantify and further explore these findings through a survey of all practising consultant neurologists in the UK ('consultant' is the British term for a doctor in a medical or surgical specialty who has completed all of their specialist training).

\section{METHODS}

A postal survey was sent to all practising consultant neurologists registered with the Association of British Neurologists (ABN). The survey (see appendix 1, available online only) contained 33 questions, largely multiple choice but with some free text, first covering demographics and details of the clinician's practice and then addressing their understanding and management of CD. The covering letter stipulated that the neurologist's opinion was sought, even where they did not consider themselves particularly knowledgeable, and no definition or description of $\mathrm{CD}$ was given. One-third were given a $£ 10$ book token as an incentive, and a further third were offered a book token on completion. After approximately 1 month, a second, identical survey was sent to all those who had not responded to the first round. Data from both rounds was entered into and analysed with SPSS 16.0 (SPSS Inc). The survey was approved by the local ethics review board; response to the survey was taken to indicate consent by the neurologists. The study funders had no role in the design, execution or analysis of this research.

In this paper, we present the results from 28 of the questions. Five others (dealing with how neurologists perceive psychiatrists, how they use 'functional' and their views on chronic fatigue syndrome) will be presented elsewhere. 


\section{RESULTS \\ Respondents}

The ABN supplied a list of 634 names and addresses. Thirteen of these were overseas and five were known by the authors to be non-neurologists (eg, one of the authors of this paper), leaving 616 names. Three hundred and nineteen (52\%) responded to the first round, a further 57 responded to the second round, for an aggregate response of 376 (62\%), plus five that were returned 'addressee unknown'. Twenty-seven of these were not included in the analysis, however, either because they did not complete the survey $(n=7)$ or because they gave us reason to exclude their responses. Reasons were: being a neurophysiologist $(n=8)$ or other non-neurologist $(n=5)$; or being retired $(n=3)$, on long term sick leave $(n=1)$ or otherwise not seeing patients $(n=3)$. Excluding those who were not practising neurologists gave an adjusted completion rate of 349 from 591 eligible subjects (59\%). Although the incentives encouraged a response, they did not appear to introduce a bias. ${ }^{7}$

In contrast with a previous survey of UK neurologists on this topic, ${ }^{8}$ there were extensive comments and amendments made by the respondents. These were sometimes simply complimentary ("nice survey!") or critical ("What do you mean by conversion disorder?") but were often 'running commentaries' on the questions and occasionally were extended responses-for example, in accompanying letters.

Demographics and clinical background of the respondents (questions $1-5,29$ ) are given in table 1 . This reveals them to be very largely male, of median late forties in age, overwhelmingly trained in the British Isles, having worked for an average of 19.5 years in neurology and, in $43 \%$ of cases, with some training in psychiatry or neuropsychiatry. Female neurologists were marginally younger on average (median in their early forties compared with late forties for men, $p=0.02$, Mann-Whitney $U$ test), with fewer years in neurology (median 14 vs 19 years, $\mathrm{p}=0.001$, Mann - Whitney $U$ test). Ten per cent of neurologists reported having had a personal experience of $\mathrm{CD}$ before they studied medicine, either in themselves, their family (most commonly their mother) or a friend, with twice the proportion of neurologists trained in developing countries ( $p=0.048$, Fisher's exact test) having experienced CD in their families. Prior experience of CD did not correlate with any particular view, however, other than to make the neurologist more interested (as demonstrated by their being more likely to describe cases or to expand on 'other' selections when offered the chance). The neurologists reported seeing between one and 320 new patients per month but the upper bound seemed implausible so we assumed that at least some of the respondents had misread the question and have not considered it further.

\section{The nature of conversion disorder}

The responses to the questions on the nature of $\mathrm{CD}$ (questions $5-9,11-15,31)$ are given in table 2 . They show that the great majority reported that patients with medically unexplained symptoms comprised less than a quarter of their new referrals, and that patients with CD were a minority of those, though almost a quarter thought most of their unexplained patients had $\mathrm{CD}$. Consistent with this, the most common view was that CD was a particular subset of the unexplained, although more than half saw it as a distinct, but perhaps overlapping, condition. When asked about brief case vignettes, only $1 \%$ found the lack of apparent psychological problems to preclude the diagnosis whereas $6 \%$ thought having only a minor tingle was not sufficient and $17 \%$ thought that symptoms that were better when thought unobserved could not possibly be CD.
Table 1 Demographic and clinical background of respondents' percentages are of those answering the question rounded to the nearest whole number

\begin{tabular}{lc}
\hline Characteristic & $\mathbf{N}(\%)$ \\
\hline Gender & \\
Male & $286(82)$ \\
Female & $62(18)$ \\
Age (years) & \\
$<41$ & $49(14)$ \\
$41-45$ & $107(31)$ \\
$46-50$ & $81(23)$ \\
$51-55$ & $48(14)$ \\
$56-60$ & $38(11)$ \\
$>60$ & $26(7)$ \\
Country of training & \\
UK and Ireland & $302(86)$ \\
Western Europe & $17(5)$ \\
Eastern Europe & $3(1)$ \\
0 ther developed countries & $12(3)$ \\
Developing countries & $15(4)$ \\
Years working in neurology & \\
$3-10$ & $11(3)$ \\
$10-19$ & $173(50)$ \\
$20-29$ & $106(32)$ \\
$30-47$ & $54(16)$ \\
Months working in psychiatry & \\
0 & $256(74)$ \\
$1-3$ & $34(10)$ \\
$4-6$ & $29(8)$ \\
$7-12$ & $19(6)$ \\
$13-100$ & $9(3)$ \\
Months working in neuropsychiatry & \\
0 & $256(74)$ \\
$1-3$ & $40(12)$ \\
$4-6$ & $37(11)$ \\
$7-150$ & $13(4)$ \\
Experience of conversion before medicine & \\
None & $331(90)$ \\
In self & $7(2)$ \\
In family member & $9(3)$ \\
In friend & \\
\hline &
\end{tabular}

The most popular explanatory model was the Freudianseeming 'subconscious', followed by the behavioural 'abnormal illness behaviour', which were both far more commonly chosen than the more neurological-seeming 'disordered brain function' or 'effects of stress on the nervous system'-particularly so for female neurologists ( $p=0.001$, Fisher's exact test) where 40/60 (67\%) preferred 'subconscious' explanations compared with 122/ $282(43 \%)$ of male neurologists. Yet fewer than half of respondents thought psychiatrists had a sufficient psychological explanation.

Explanations in terms of feigning were more nuanced: while the vast majority thought only a few of their conversion patients were feigning, only a minority saw the two as fully distinct, with most opting for a more entangled relationship between conversion and feigning, including 13\% who thought all of their conversion patients were feigning, or vice versa. The nature of this relationship was significantly determined by the age of the neurologist ( $p=0.001, F=5.3$ ) and the number of years they had practised neurology $(p<0.001, F=6.2)$, with older neurologists seeing the two as less distinct. More broadly, this question seemed to identify clear subgroups of neurologists. Those who thought conversion and feigning completely distinct 
Table 2 Neurologists' views on the nature of conversion disorder

\begin{tabular}{|c|c|}
\hline & N (\%) \\
\hline \multicolumn{2}{|c|}{ Percentage of new patients' symptoms with no sufficient neurological basis } \\
\hline$<10 \%$ & $95(27)$ \\
\hline $10-25 \%$ & $196(56$ \\
\hline $25-50 \%$ & $51(15$ \\
\hline$>50 \%$ & $5(1)$ \\
\hline \multicolumn{2}{|l|}{ Proportion of these with conversion disorder } \\
\hline All or virtually all & $1(0)$ \\
\hline The majority & $81(24$ \\
\hline A minority & $247(73$ \\
\hline None & $5(2)$ \\
\hline \multicolumn{2}{|l|}{ Relationship of conversion to other unexplained } \\
\hline Overlap & $139(41)$ \\
\hline Completely distinct & $39(11)$ \\
\hline Unexplained a subset of conversion & $9(3)$ \\
\hline Conversion a subset of the unexplained & $155(45$ \\
\hline \multicolumn{2}{|c|}{ How likely is a diagnosis of conversion disorder in } \\
\hline \multicolumn{2}{|c|}{ A woman with inconsistent paralysis who appears psychologically healthy? } \\
\hline Impossible & $3(1)$ \\
\hline Possible & $215(62$ \\
\hline Probable & $128(37)$ \\
\hline \multicolumn{2}{|c|}{ A distressed man with an unexplained arm tingle? } \\
\hline Impossible & $20(6)$ \\
\hline Possible & $292(85)$ \\
\hline Probable & $30(9)$ \\
\hline \multicolumn{2}{|c|}{ A man whose paralysis improves when he thinks he's not observed? } \\
\hline Impossible & $58(17)$ \\
\hline Possible & $162(47)$ \\
\hline Probable & $125(36$ \\
\hline \multicolumn{2}{|c|}{ Do psychiatrists have a sufficient psychological model for conversion? } \\
\hline Yes & $10(3)$ \\
\hline Probably & $40(12)$ \\
\hline Possibly & $107(32$ \\
\hline No & $180(53$ \\
\hline \multicolumn{2}{|c|}{ Which model best explains your view of conversion disorder? } \\
\hline Effects of stress on the nervous system & $38(11$ \\
\hline Subconscious behaviour & $163(47)$ \\
\hline Disorder of brain function & $26(7)$ \\
\hline Abnormal illness behaviour & $66(19)$ \\
\hline Feigning & $2(1)$ \\
\hline Other (or several of the above) & $49(14$ \\
\hline \multicolumn{2}{|c|}{ What proportion of your unexplained patients do you think are feigning? } \\
\hline None & $27(8)$ \\
\hline A few & $302(88$ \\
\hline Many & $13(4)$ \\
\hline Most or all of them & $2(1)$ \\
\hline \multicolumn{2}{|l|}{ Relationship of conversion to feigning } \\
\hline Overlap & $150(44)$ \\
\hline Completely distinct & $151(44$ \\
\hline Feigning a subset of conversion & $30(9)$ \\
\hline Conversion a subset of feigning & $13(4)$ \\
\hline \multicolumn{2}{|c|}{ Do you understand conversion to be neurological, in the same way as MS? } \\
\hline Yes & $35(10)$ \\
\hline No, but I expect to one day & $89(26)$ \\
\hline No, and I expect I never will & $219(63)$ \\
\hline
\end{tabular}

Percentages are of those answering the question rounded to the nearest whole number. MS, multiple sclerosis.

were unsurprisingly more likely $\left(p<0.001, \chi^{2}=36.9, \mathrm{df}=6\right)$ to think that symptoms that improved when thought unobserved precluded a diagnosis of $\mathrm{CD}$ and to think that none of their conversion patients were feigning $\left(p<0.001, \chi^{2}=41.5, \mathrm{df}=9\right)$. Contrasting these neurologists with those who thought conversion to be just a type of feigning showed the latter to be older (median late fifties, vs late forties, $p=0.01$,
Mann-Whitney $U$ test) and more likely to have trained in developing countries $\left(p=0.019, \chi^{2}=5.5, d f=1\right)$. Their preferred model for conversion was in terms of abnormal illness behaviour $\left(p=0.003, \chi^{2}=19.5, d f=6\right)$ and they differed on their approaches to diagnosis and to communication, as we discuss in those sections hereafter.

The neurologists were asked to give an example of a memorable case and 124 did so, describing a range of presentations, most commonly weakness/paralysis $(n=46)$ or seizures $(n=29)$. A qualitative rating of what was distinctive about these cases was made. Where it was possible to reach a judgement (109 cases), this was most commonly (37 cases) because they seemed 'classic' cases (life stressors leading to symptoms of a symbolic or adaptive nature, such as a hand dystonia arising when having to sign an important document) although often ( 28 cases) it was because of the dramatic nature of the presenting symptom (such as sudden blindness) or of the patient or their circumstances (15 cases) (such as being an ex-Special Forces soldier). However, in 14 cases what seemed to have made it memorable was the apparent deception or conscious control (such as a 'paraplegic' walking to the bathroom when thought unobserved).

When asked whether CD was neurological in the same way that multiple sclerosis was, $63 \%$ felt it was not and did not think that view would change. This was answered differently by gender $\left(p<0.001, \chi^{2}=15.6, d f=2\right)$ and by cultural background $\left(p=0.03, \chi^{2}=7.0, d f=2\right)$, with $58 \%$ of female neurologists and two-thirds of those trained in developing countries either thinking that conversion was like multiple sclerosis or expecting to think so one day.

\section{Diagnosing conversion disorder}

When it came to making the diagnosis, the majority felt they could do so very $(16 \%)$ or fairly $(67 \%)$ confidently. They reported using the criteria in table 3 in making their diagnosis. This showed that although the overwhelmingly favourite criterion was inconsistency, and that 'dislikeable', 'symptom severity', 'disability' or 'amount of work' were the most important for only a handful of neurologists, all of the characteristics were endorsed as useful by substantial percentages of the neurologists: the more 'psychiatric' aspects of abnormal illness behaviour and psychological abnormality were diagnostically important to large majorities, and even the more personal 'dislikeable' and 'amount of work for you' were endorsed by many. Observer dependence was middle weighted, with 59\% feeling it was useful-although this might either have been useful in confirming conversion or in excluding the differential of feigning, depending on the neurologist's view (see figure 1). Those who thought conversion was merely a kind of feigning were more likely to diagnose it on the basis of the amount of work the patient caused them $\left(p=0.001, \chi^{2}=30.7, d f=5\right)$ or the degree of disability they showed $\left(\mathrm{p}=0.048, \chi^{2}=11.2, \mathrm{df}=5\right)$, and less likely to base it on the presence of psychiatric abnormality $(p=0.043$, Fisher's exact test) than those who thought it a distinct entity.

\section{Communication with patients}

The neurologists' views on communicating with patients in this area (questions 21-8) are given in table 4. A slight majority (51\%) thought that giving the diagnosis was easier now than it was for those who trained them, although there was a significant effect of age on this $\left(p=0.03, \chi^{2}=12.3, d f=5\right)$, with every age group under 60 years finding it easier now, but those over 60 not finding it easier, by 4 to 1 . Most neurologists (97\%) attempted to give an explanatory model to the patient if asked, and if the patient seemed receptive, the neurologists would 
Table 3 Diagnostic utility of patient characteristics

\begin{tabular}{lccc}
\hline & $\begin{array}{l}\text { Rated as most } \\
\text { important ('1') } \\
\text { (n (\%)) }\end{array}$ & $\begin{array}{l}\text { Rated as } \\
\text { useful ('1' to '5') } \\
\text { (n (\%)) }\end{array}$ & $\begin{array}{l}\text { Rated as not } \\
\text { useful (''x') } \\
\text { (n (\%)) }\end{array}$ \\
\hline Inconsistency & $173(51)$ & $315(93)$ & $14(5)$ \\
Amount of work for you & $6(2)$ & $51(15)$ & $221(72)$ \\
Symptom type & $67(20)$ & $278(82)$ & $31(10)$ \\
Abnormal illness behaviour & $70(21)$ & $289(86)$ & $15(5)$ \\
Disability & $8(2)$ & $109(32)$ & $129(42)$ \\
Psychological abnormality & $30(9)$ & $260(77)$ & $35(11)$ \\
Symptom severity & $4(1)$ & $104(31)$ & $129(42)$ \\
Dislikeable & $2(1)$ & $41(12)$ & $266(87)$ \\
Observer dependence & $24(7)$ & $199(59)$ & $41(13)$ \\
\hline
\end{tabular}

Respondents ranked five characteristics they used to make the diagnosis in declining order of importance from 1 to 5 . Where respondents ranked all five equally (eg, using ticks rather than numbers) all were considered as ' 1 ' for this table. Respondents also marked any characteristics with an ' $x$ ' that they did not use. Percentages are of those answering the question rounded to the nearest whole number.

always (58\%) or usually (38\%) talk about psychological factors. When the patient seemed resistant, things slipped somewhat, with $17 \%$ saying they would rarely or never discuss psychology. The model offered correlated well with the model the neurologist believed (contingency coefficient $=0.6, p<0.001$ ), when that model was restricted to stress, the subconscious or disordered brain function, but those who believed feigning or abnormal illness behaviour best explained CD did not present it to patients in those terms. Talking about feigning was not popular, with only $18 \%$ always or usually addressing the issue when it was suspected, and just under a third addressing it even when they were certain the patient was feigning. This did not mean that the neurologists felt it was not their responsibility $-51 \%$ thought it was, with only $13 \%$ thinking it should be ignored. The neurologist's gender proved a significant determinant of communication preferences, with women more ready to discuss psychological factors $\left(\mathrm{p}=0.019, \chi^{2}=7.9, \mathrm{df}=2\right)$ when the patient

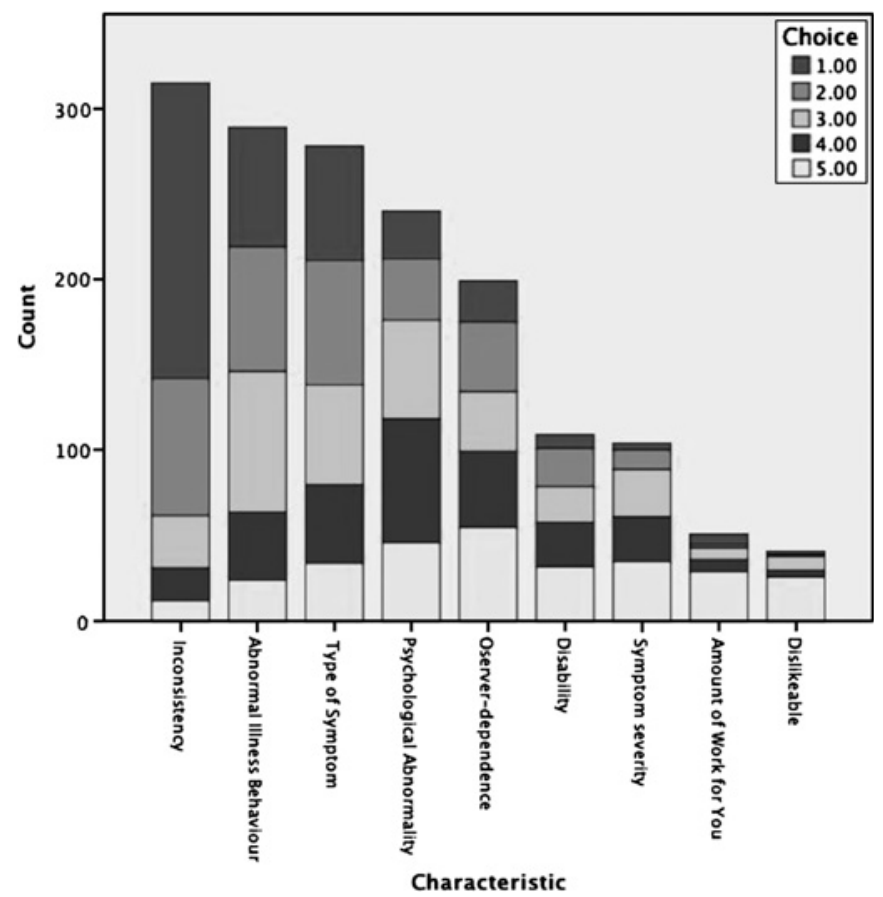

Figure 1 Neurologists' preferred diagnostic characteristics for conversion disorder. A characteristic marked ' 1 ' was considered the most important and ' 5 ' the least important. was receptive, or feigning when it was suspected ( $p=0.049$, $\chi^{2}=7.9, \mathrm{df}=3$ ). Whereas the majority of men found it no easier to give $\mathrm{CD}$ diagnoses today, women found it easier by more than 2 to 1 ( $p=0.002$, fisher's exact test). In contrast, those who thought $\mathrm{CD}$ a special kind of feigning were much less likely to discuss psychological factors $\left(p=0.002, \chi^{2}=12.1, d f=2\right)$ with a receptive patient, and more than 5 to 1 did not find it easier to talk about $C D$ today ( $p=0.022$, Fisher's exact test) compared with those who thought $\mathrm{CD}$ and feigning fully distinct.

Neurologists were closely divided on the desirability of copying letters to patients with CD. Just over a third always or usually used codes or euphemisms when writing to the primary care physician (general practitioner (GP)) - with $79 \%$ doing so at least occasionally; the codes were most commonly used to inform the GP that the patient had $\mathrm{CD}$ or a psychological problem.

\section{DISCUSSION}

The good response rate to a lengthy postal survey shows that neurologists continue to be galvanised by this patient group. The results tended to confirm the findings of our qualitative study $^{5}{ }^{6}$ while permitting a more complex interpretation and refuting some aspects. The neurologists endorsed psychological models for conversion over neurological or behavioural models but it was the latter which they tended to employ diagnostically, a finding confirmed in a recent survey of international (principally American) neurologists. ${ }^{9}$ Indeed, most thought that even psychiatrists could not really explain $C D$ psychologically. Ultimately, the neurologists' fondness for the psychologically opaque 'abnormal illness behaviour' ${ }^{10}$ as an explanation and as a diagnostic device supports the view that the neurologists would rather remain non-committal as to the motivations or consciousness of their patients' behaviour. That would mean that feigning remained a possibility, of course, and the neurologists' views on the relationship of $\mathrm{CD}$ with feigning were as complex as expected. Although there were few (but not none) who thought feigning the best model for $\mathrm{CD}$, most thought they were not fully distinct, and one in eight thought one was just a particular type of the other. There were clues from other questions too, that hinted at a more prominent role for feigning in neurologists' thinking than their preferred model would suggest-the deception cited in memorable cases, the codes signalling to the GP that there was 'nothing really wrong' with the patient, the diagnostic overlap. In all cases these were minority responses but they occurred at higher rates than the mere handful who bluntly stated that feigning was their preferred model, suggesting it has a deeper and broader root in the neurologists' conception of $\mathrm{CD}$. We argued earlier ${ }^{5}$ that its root may be foundational-CD as a kind of medical deception that may (or may not, agnostically) be explained psychologically.

The neurologists' communication preferences reflected the nuance of our qualitative findings - that the neurologists were guided by the receptivity of their patients as to how psychological to make their eventual explanations but did not discuss their suspicions about feigning, even if sure of it. This pattern in the qualitative study led to the concern that this would lead to changed diagnoses-either as CD cases would be 'downgraded' to a 'simply unexplained' or as cases of feigning would be allowed to carry the diagnosis of $\mathrm{CD}$ or some other unexplained condition. ${ }^{6}$ The evidence from this survey is that neurologists usually were willing to talk about psychological factors, even when the patient resisted, so the first kind of downgrading 
Table 4 Neurologists' views on communication in conversion disorder and feigning

\begin{tabular}{|c|c|}
\hline & $\mathbf{N}(\%)$ \\
\hline \multicolumn{2}{|c|}{ Which model do you use to explain conversion disorder, if patients ask? } \\
\hline Effects of stress on the nervous system & $119(34)$ \\
\hline Subconscious behaviour & $94(27)$ \\
\hline Disorder of brain function & $45(13)$ \\
\hline Mind over matter & $12(4)$ \\
\hline I can't explain it & $10(3)$ \\
\hline Other (or several of the above) & 67 (19) \\
\hline \multicolumn{2}{|c|}{$\begin{array}{l}\text { Do you refer to psychological factors when explaining your diagnosis in conversion } \\
\text { patients-if they seem open to it? }\end{array}$} \\
\hline Always & $203(58)$ \\
\hline Usually & $130(38)$ \\
\hline Rarely & $14(4)$ \\
\hline Never & $0(0)$ \\
\hline \multicolumn{2}{|l|}{ If they seem resistant? } \\
\hline Always & $86(25)$ \\
\hline Usually & $200(58)$ \\
\hline Rarely & $51(15)$ \\
\hline Never & $5(2)$ \\
\hline \multicolumn{2}{|c|}{ Do you talk about feigning with patients-if you suspect it? } \\
\hline Always & $6(2)$ \\
\hline Usually & $54(16)$ \\
\hline Rarely & $151(44)$ \\
\hline Never & $133(39)$ \\
\hline \multicolumn{2}{|l|}{ If you're sure of it? } \\
\hline Always & $39(12)$ \\
\hline Usually & $69(20)$ \\
\hline Rarely & $137(41)$ \\
\hline Never & $91(27)$ \\
\hline \multicolumn{2}{|l|}{ Who should address feigning in your patient?* } \\
\hline $\mathrm{Me}$ & $158(51)$ \\
\hline The GP & $64(21)$ \\
\hline A psychiatrist & $87(28)$ \\
\hline The police or some other agency & $49(16)$ \\
\hline No-one & $39(13)$ \\
\hline \multicolumn{2}{|c|}{$\begin{array}{l}\text { Does giving the diagnosis of conversion seem easier now than for those } \\
\text { who trained you? }\end{array}$} \\
\hline Yes & $168(51)$ \\
\hline No & $163(49)$ \\
\hline \multicolumn{2}{|c|}{ Do you copy letters about your conversion patients to them? } \\
\hline I prefer to & $175(53)$ \\
\hline I prefer not to & $154(47)$ \\
\hline \multicolumn{2}{|l|}{ Do you use 'codes' or euphemisms in those letters? } \\
\hline Always & $11(3)$ \\
\hline Usually & $101(31)$ \\
\hline Rarely & $149(45)$ \\
\hline Never & $69(21)$ \\
\hline \multicolumn{2}{|c|}{ What do you hope the GP will understand by your codes?* } \\
\hline That the patient has a conversion disorder & $155(45)$ \\
\hline That their problem is psychological & $156(45)$ \\
\hline That there is nothing really wrong with them & $23(7)$ \\
\hline Other & $17(5)$ \\
\hline
\end{tabular}

Percentages are of those answering the question rounded to the nearest whole number. *Scored allowing multiple selections.

$\mathrm{GP}$, general practitioner (primary care physician).

seemed likely to be rare; the concern about feigning seemed to be more justified, however, a finding supported by our review ${ }^{11}$ of published cases of factitious neurology which suggested the bulk of them may be diagnosed as CD.

Such a summary tends to gloss over the wide differences the survey revealed, and the neurologists presented as a diverse group. Still, trends could be discerned within UK neurologists as a whole, with the age of the neurologist featuring prominently in attitudes to feigning. A smaller, older group believed CD to be a kind of feigning, to diagnose it more on the basis of associated negatives (more disabled, more work to manage) was, perhaps consequently, less prepared to discuss the psychological aspects with their patients and found communicating the diagnosis no easier than it had been in the past. Female neurologists tended to be younger, were more inclined to psychiatric models, more willing to communicate with their patients about psychological factors or feigning and generally found communication easier. Their greater support for a potential neurological basis for CD may help them to talk about issues that many patients fear are just shorthand for feigning, a fear that finds some justification from our survey. It may be that the shift towards better communication is not in conflict with frank disclosure, as our qualitative study suggested, but in part because the views of younger neurologists are more acceptable to patients.

\section{Limitations}

Any survey will shape the responses of those who respond; it will limit their choices and guide them to answers they may not have otherwise considered. So, for example, asking neurologists to choose five discriminating features may have encouraged them to consider more features than they would normally.

This survey, and the interviews that shaped it, examined neurologists' self-reports of their communication in CD: they did not directly examine neurologists' communication, which may be considerably different, and are even further removed from how patients experience the neurologist's communication. The evidence from somatoform disorders in general suggests considerable miscommunication between doctor and patient: that patients' receptivity to psychosocial explanations is poorly detected, ${ }^{12}$ that attempts at persuasion are deflected or resisted ${ }^{13}$ and that a message of implied feigning is still strongly heard. ${ }^{3}$

The 22 neurologists who were interviewed before the survey, and whose responses shaped it, were not selected to be a representative sample but to offer as wide a range of views as possible, so the survey may have been particularly inclined to look for unusual views. But the neurologists who responded to the survey were not statistically different from those interviewed on any aspect of their background or training, except that the striking proportion $(9 / 22,41 \%)$ of neurologists interviewed who reported exposure to $\mathrm{CD}$ before going into medicine ${ }^{6}$ was not replicated in the survey $\left(p<0.0001, \chi^{2}=22.3, d f=1\right)$. Although, at $10 \%$, the national rate of those reporting prior exposure to conversion is not insubstantial and would merit consideration as a risk factor for choosing a career in neurology if it was shown to be substantially higher than the background rate.

We did not offer a definition of CD, and there may have been some doubt about which patients it included, as suggested by the critical comment noted above, for example, with possible bias resulting. However, the depth interviews that preceded this survey found that all of the neurologists understood the concept $^{5}$ and it is a term in common enough use among neurologists, albeit not the most popular. ${ }^{9}$ Offering a definition, such as the one included in psychiatric classification, would probably have introduced even greater bias as responses were adjusted to match. Even our use of the term 'conversion disorder' rather than any of the alternatives may have inclined respondents to think in more Freudian terms.

This was a survey of UK neurologists and their responses cannot be extended to other countries without qualification (there are no comparable surveys that we are aware of from other countries, although one recent survey of American neurologists on non-epileptic seizures suggests they may be 
particularly willing to discuss psychological factors ${ }^{14}$ ). And we do not know, ultimately, how representative the respondents are of UK neurologists as a whole, although we believe the sample frame included all of them. There is no statutory body in the UK specific to neurologists (rather they are included in general physician bodies), with the closest thing to such a body being the $A B N$, an organisation that was constituted to include all consultant neurologists in the UK (http://www.theabn.org/ AboutTheABN/History.aspx). We sent surveys to all of their consultant members and had responses from over $60 \%$ of them, so we would expect to have the views of the majority of UK neurologists included in our findings; but the $40 \%$ who did not respond may have harboured very different views, of course, and may have not responded because of them. Yet if these are the responses of neurologists with a particular interest in $\mathrm{CD}$, then what remains remarkable is the wide variety of views held. A clinical problem that baffled neurologists in the nineteenth century continues to puzzle them more than a century later.

Acknowledgements The authors would like to thank the neurologists who gave their time to complete the survey, and the Association of British Neurologists for their assistance with the mailing list

Funding RAK was supported by a Biomedical Ethics Fellowship from the Wellcome Trust (grant No 079743). SCW was partially funded by the South London and Maudsley NHS Foundation Trust//nstitute of Psychiatry NIHR (National Institute of Health Research) Biomedical Research Centre.

\section{Competing interests None.}

Ethics approval This study was conducted with the approval of King's College Research Ethics Committee.

Contributors All authors were involved in procuring funding, devising the questionnaire and drafting the manuscript. RAK \& DA managed the data entry and conducted the statistical analysis. RAK arranged ethics approval, set up the study and managed the survey distribution.

Provenance and peer review Not commissioned; externally peer reviewed.

\section{REFERENCES}

1. Hallett M. Psychogenic movement disorders: a crisis for neurology. Curr Neurol Neurosci Rep 2006;6:269-71.

2. Kanaan RA, Wessely SC. The origins of factitious disorder. Hist Human Sci 2010;23:68-85.

3. Nettleton S, Watt I, O'Malley L, et al. Understanding the narratives of people who live with medically unexplained illness. Patient Educ Couns 2005;56:205-10.

4. Thompson R, Isaac CL, Rowse G, et al. What is it like to receive a diagnosis of nonepileptic seizures? Epilepsy Behav 2009;14:508-15.

5. Kanaan R, Armstrong D, Barnes P, et al. In the psychiatrist's chair: how neurologists understand conversion disorder. Brain 2009;132:2889-96.

6. Kanaan R, Armstrong D, Wessely S. Limits to truth-telling: neurologists communication in conversion disorder. Patient Educ Couns 2009;77:296-301.

7. Kanaan RA, Wessely SC, Armstrong D. Differential effects of pre and post-payment on neurologists' response rates to a postal survey. BMC Neurol 2010;10:100.

8. Mace CJ, Trimble MR. 'Hysteria', 'functional' or 'psychogenic'? A survey of British neurologists' preferences. J $R$ Soc Med 1991;84:471-5.

9. Espay AJ, Goldenhar LM, Voon V, et al. Opinions and clinical practices related to diagnosing and managing patients with psychogenic movement disorders: an international survey of movement disorder society members. Mov Disord 2009;24:1366-74.

10. Pilowsky I. A general classification of abnormal illness behaviours. Br J Med Psychol 1978:51:131-7.

11. Kanaan RA, Wessely SC. Factitious disorders in neurology: an analysis of reported cases. Psychosomatics 2010;51:47-54.

12. Ring A, Dowrick CF, Humphris GM, et al. The somatising effect of clinical consultation: what patients and doctors say and do not say when patients present medically unexplained physical symptoms. Soc Sci Med 2005;61:1505-15.

13. Burbaum C, Stresing AM, Fritzsche K, et al. Medically unexplained symptoms as a threat to patients' identity? A conversation analysis of patients' reactions to psychosomatic attributions. Patient Educ Couns 2010;79:207-17.

14. LaFrance WC Jr, Rusch MD, Machan JT. What is "treatment as usual" for nonepileptic seizures? Epilepsy Behav 2008;12:388-94 